\title{
PENGARUH PENGETAHUAN KONSUMEN, KUALITAS PRODUK DAN KEPERCAYAAN KONSUMEN TERHADAP LOYALITAS PELANGGAN PADA PENGISIAN ANGIN MEREK GREEN NITROGEN
}

\author{
THE INFLUENCE OF CONSUMER KNOWLEDGE, PRODUCT QUALITY, AND CONSUMER TRUST ON \\ CONSUMER LOYALTY OF GREEN NITROGEN
}

\author{
Mutammam*), Ujang Sumarwan $^{* *)}$, dan Netti Tinaprilla $\left.{ }^{* * *}\right)$ \\ *) Sekolah Bisnis, Institut Pertanian Bogor \\ Jl. Raya Pajajaran, Bogor 16151 \\ **) Departemen Ilmu Keluarga dan Konsumen, Fakultas Ekologi Manusia, Institut Pertanian Bogor \\ Kampus IPB Dramaga, Bogor 16680 \\ ${ }^{* * *}$ Departemen Agribisnis, Fakultas Ekonomi dan Manajemen, Institut Pertanian Bogor \\ Jl. Agatis Kampus IPB Darmaga, Bogor 16680
}

\begin{abstract}
Green Nitrogen is one of the nitrogen service brands in Indonesia available at some Pertamina Gas Stations. The purposes of this research were to examine the effect of consumer knowledge, product quality, and consumer trust on customer loyalty, and to formulate strategies to increase consumer loyalty. This research used Structural Equation Model (SEM) analytical tool. The result indicated that factors affecting Green Nitrogen consumer loyalty were sequentially starting from the highest $R$-Square value with the most significant effect was consumer trust with a weight of 0.371; then, the product quality with a weight of 0.136, and consumer knowledge with a weight of 0.093. The results of $t$ values indicated that consumer knowledge and product quality have no significant effect on consumer loyalty. The process of consumer loyalty is affected by how much trust the consumers have on Green Nitrogen's reputation and responsibilities in dealing with claims proposed by consumers compared with the elements of product quality and consumer knowledge. Therefore, Green Nitrogen needs to create a platform to accommodate complaints, claims, and suggestions from its consumers so that the consumers feel satisfied with the services provided.
\end{abstract}

Keywords: custoumer knowledge, product quality, customer trust, customer loyalty, Structural Equation Modeling (sem)

\begin{abstract}
Abstrak: Green Nitrogen merupakan salah satu merek penyedia jasa pengisian angin nitrogen yang terdapat di beberapa Stasiun Pengisian Bahan Bakar (SPBU) Pertamina di Indonesia. Tujuan dari penelitian ini untuk mengetahui pengaruh pengetahuan konsumen, kualitas produk, dan kepercayaan konsumen terhadap loyalitas pelanggan serta menyusun strategi pemasaran untuk meningkatkan loyalitas pelanggan. Alat analisis yang digunakan dalam penelitian ini adalah Structural Equation Modeling (SEM). Hasil penelitian menunjukkan bahwa faktor-faktor yang berpengaruh terhadap loyalitas pelanggan Green Nitrogen secara berurutan dari nilai R-Square terbesar adalah kepercayaan pelanggan dengan bobot 0,371 , kualitas produk dengan bobot 0,136 dan pengetahuan konsumen dengan bobot 0,093 . Nilai t menunjukkan bahwa pengetahuan konsumen dan kualitas produk tidak berpengaruh signifikan terhadap loyalitas pelanggan. Proses loyalitas pelanggan banyak dipengaruhi oleh seberapa besar konsumen memiliki kepercayaan atas reputasi dan tanggung jawab Green Nitrogen atas klaim yang diajukan pelanggan dibandingkan elemen-elemen pembentuk kualitas produk dan pengetahuan konsumen. Oleh sebab itu, Green Nitrogen perlu membuat wadah untuk menampung pengaduan, klaim dan saran dari pelanggannya agar pelanggan merasa puas atas pelayanan yang telah diberikan.
\end{abstract}

Kata kunci: pengetahuan konsumen, kualitas produk, kepercayaan pelanggan, loyalitas pelanggan, struktural equation model (sem)

\footnotetext{
${ }^{1}$ Corresponding author:

Email: mutammam_tammam@yahoo.co.id
} 


\section{PENDAHULUAN}

Industri otomotif merupakan salah satu pilar terpenting dalam sektor manufaktur di Indonesia karena terdapat banyak perusahaan mobil dengan merek terkenal membuka pabrik-pabrik manufaktur di Indonesia. Indonesia memiliki industri manufaktur mobil terbesar kedua di Asia Tenggara dan di wilayah ASEAN. Penjualan mobil di Indonesia terus mengalami peningkatan setiap tahunnya, yang juga diiringi dengan meningkatnya kesadaran konsumen untuk menjaga performa dari kendaraannya sendiri.

Salah satu performa dari kendaraan yang diperhatikan pemilik kendaraan adalah performa ban karena terkait dengan keselamatan berkendara. Salah satu cara menjaga performansi ban kendaraan yaitu dengan memperhatikan pengisian angin pada ban tersebut. Pengisian angin bisa dilakukan dengan angin biasa (udara) atau gas nitrogen. Meskipun demikian, pengisian angin (udara) lebih murah dan bisa didapatkan gratis dibandingkan dengan gas nitrogen. Namun, kualitas dan manfaat nitrogen jauh berbeda dibanding angin biasa. Kelebihan kualitas nitrogen diantaranya memiliki partikel gas yang lebih besar sehingga daya cengkram ban lebih stabil dan meringankan kerja mesin dan pada akhirnya menghemat BBM (Bahan Bakar Minyak).

Pengetahuan konsumen akan manfaat angin nitrogen dibanding angin biasa berawal dari toko ban besar dan bengkel besar. Toko ban besar memberi bonus pengisian angin nitrogen untuk pembelian ban dan menjelaskan manfaat angin nitrogen bagi ban. Demikian juga bengkel besar memberikan tambahan layanan berupa pengisian angin nitrogen. Konsumen yang telah merasakan manfaat kelebihan angin nitrogen ini akan terus mengisi ulang ban kendaraan dengan angin nitrogen juga.

Kebutuhan pengisian angin nitrogen ini mendorong pengusaha ekonomi kreatif untuk menghadirkan layanan pengisian angin nitrogen yang mudah dijangkau pengendara mobil. Tempat yang paling mudah dijangkau adalah SPBU, karena selain menjadi tempat pengisian bahan bakar juga terdapat fasilitas lain yaitu tempat peristirahatan atau rest area, minimarket, restoran, ATM dan lain lain. Dengan demikian, di banyak SPBU sering ditemukan pengisian angin nitrogen dengan berbagai merek. Saat ini outlet pengisian nitrogen di SPBU terus bertambah menjadi lebih 1000 outlet dengan lebih dari 10 merek.
Salah satu merek pengisian angin nitrogen di SPBU adalah Green Nitrogen. Merek Green Nitrogen sangat berbeda dibanding merek lain dengan penampilan sebariskalimatdibawahnya "keep thetireperformance". Di bagian dalam, terdapat backdrop berwarna dasar merah yang mencatat tujuh manfaat nitrogen, dan aneka informasi seperti kandungan nitrogen yang dihasilkan dan beragam layanan beserta tarifnya (Wijaya, 2013). Saat ini Green Nitrogen semakin serius dalam pengelolaan bisnis tidak hanya dari segi peningkatan kualitas dan layanan namun juga penambahan jumlah outlet dari tahun ke tahun di SPBU yang tersebar di seluruh Indonesia. Green Nitrogen terus menambah jumlah outlet dari 2014 sebanyak 240 outlet menjadi 625 outlet pada 2018 (Gambar 1)

Terdapat permasalahan yang dihadapi Green Nitrogen, yakni persaingan antar merek dan isu pengisian nitrogen palsu. Green Nitrogen harus meyakinkan konsumen bahwa nitrogen yang dipakai memiliki kualitas atau kemurnian yang tinggi, mempunyai pelayanan yang baik, bahkan mendapat beberapa award atau penghargaan. Upaya itu untuk membuat pelanggan memilih dan tetap loyal terhadap Green Nitrogen. Loyalitas adalah hal yang penting, karena dengan memperkuat loyalitas pelanggan, bisnis dapat mempertahankan pelanggan dan akibatnya keuntungan meningkat (Hong dan Cho, 2011).

Belum ada penelitian sebelumnya yang mengukur loyalitas konsumen terhadap pembelian angin nitrogen khususnya dengan merek Green Nitrogen. Pemberian merek terhadap barang komoditas atau barang yang tersedia di alam bebas seperti udara, tidak banyak dilakukan, karena barang tersebut dapat diperoleh secara gratis. Penelitian loyalitas terhadap barang komoditas atau barang bebas di alam yang diberi merek seperti Green Nitrogen sangat penting agar bisnis ini atau yang sejenis bisa terus berkembang. Penting juga menganalis faktor yang berpengaruh terhadap loyalitas pelanggan.

Penelitian Komejani dan Mohaghegh (2017) menunjukkan bahwa pengetahuan konsumen dan loyalitas pelanggan berpengaruh positif signifikan sebesar 32\%. Menurut Mowen dan Minor (2002), pengetahuan konsumen merupakan sejumlah pengalaman yang telah dialami dan informasi tentang suatu produk atau jasa yang dimiliki seseorang. Menurut Sumarwan (2015), pengetahuan konsumen adalah semua informasi yang dimiliki konsumen mengenai 
berbagai macam produk dan jasa, serta pengetahuan lainnya yang terkait dengan produk dan jasa tersebut, dan informasi yang berhubungan dengan fungsinya sebagai konsumen. Menurut Alba dan Hutchinson (1987), konsumen dengan tingkat pengetahuan produk yang berbeda dapat mempertimbangkan kriteria produk secara berbeda dalam mengevaluasi dan menggunakan informasi walaupun dengan produk yang sama.

Hasil penelitian Devaraj et al. (2001) menunjukkan adanya hubungan positif antara kualitas produk yang diberikan oleh dealer maupun pabrik otomotif terhadap loyalitas pelanggan. Kualitas produk yang baik akan memberikan image yang baik terhadap produk tersebut sehingga akan menciptakan niat beli kembali pelanggan. Kualitas diartikan sebagai kemampuan suatu produk atau jasa dalam memenuhi kebutuhan pelanggan (Heizer dan Render, 2006). Menurut Oliver (1999), loyalitas pelanggan adalah sebuah komitmen yang sangat kuat untuk membeli kembali produk atau layanan yang disukai di masa depan dengan merek yang sama. Brucks et al. (2000) menyebutkan terdapat lima dimensi kualitas produk, yaitu easy to use (kemudahan dalam penggunaan), versatility (keleluasaan dalam penggunaan), durability (daya tahan), serviceability (kemampuan pelayanan), performance (kinerja ) dan prestige (prestise).

Penelitian tentang kepercayaan konsumen dan loyalitas pelanggan dilakukan oleh Deng et al. (2010). Hasil penelitian menunjukkan bahwa kepercayaan, kualitas layanan, nilai yang dirasakan pelanggan termasuk nilai fungsional dan nilai emosial berkontribusi untuk menghasilkan kepuasan pelanggan. Selain itu kepercayaan dan kepuasan pelanggan dan switching cost berpengaruh positif terhadap peningkatan loyalitas pelanggan. Kepercayaan konsumen adalah rasa yakin bahwa penyedia produk atau layanan kompeten dan andal dalam menepati janji serta memenuhi kebutuhan pelanggannya (Richard dan Maxwell, 2013). Penelitian lain terkait dengan keeratan hubungan pemasaran atau marketing relations adalah pentingnya kepercayaan dalam hubungan pelanggan-pemasok, dimana kepercayaan merupakan atribut kunci dari hubungan pemasok dan pelanggan dan merupakan kunci terbangunnya hubungan jangka panjang (Morgan dan Hunt, 1994).

Berdasarkan permasalahan untuk meningkatkan loyalitas pelanggan di tengah maraknya persaingan dengan merek lain, perlu dilakukan penelitian terhadap faktor faktor yang memengaruhi loyalitas pelanggan. Tujuan penelitian ini untuk mengetahui apakah pengetahuan konsumen, kualitas produk, dan kepercayaan pelanggan berpengaruh positif terhadap loyalitas pelanggan Green Nitrogen. Hasil penelitian tentang loyalitas pelanggan ini diharapkan membantu menentukan strategi pemasaran perusahaan untuk terus berkembang dan memenangkan persaingan.

Ruang lingkup penelitian dilakukan di tiga outlet yaitu SPBU Bekasi Barat, SPBU Kelapa Gading Jakarta Utara dan SPBU Utan Kayu Rawamangun Jakarta Timur sesuai pertimbangan manajemen Green Nitrogen. Ketiga outlet tersebut adalah outlet yang mempunyai tingkat pendapatan atau omzet tertinggi di Jakarta. Penelitian mencakup pemilik atau pengendara kendaraan bermotor baik roda dua maupun roda empat.

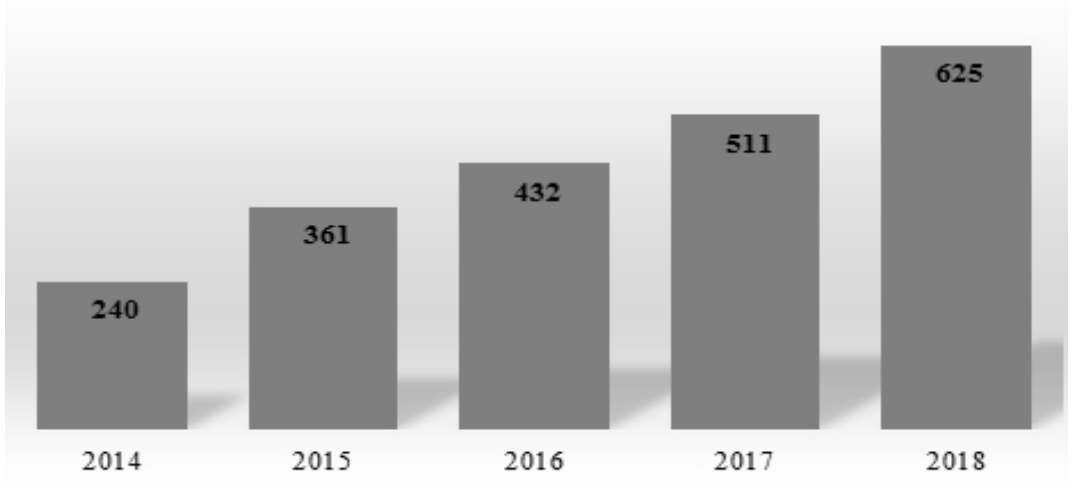

Gambar 1. Pertumbuhan jumlah outlet Green Nitrogen Tahun 2014-2018 


\section{METODE PENELITIAN}

Penelitian ini dilakukan pada bulan April 2018 di outlet yang disarankan pihak Manajemen Green Nitrogen. Penentuan lokasi penelitian dilakukan dengan sengaja (purposive) yaitu SPBU Bekasi Barat, SPBU Kelapa Gading Jakarta Utara dan SPBU Utan Kayu Rawamangun Jakarta Timur sesuai pertimbangan manajemen Green Nitrogen terkait tingkat omzet atau pendapatan outlet. Penelitian ini merupakan penelitian deskriptif yang dilakukan dengan metode survei. Pendekatan survey menggunakan daftar pertanyaan (kuesioner) ke responden.

Pengumpulan data dan informasi yang diperlukan pada penelitian menggunakan data primer dan sekunder yaitu dilakukan melalui berbagai cara, antara lain studi pustaka, observasi lapangan, wawancara dan kuesioner. Teknik pengambilan sampel yang digunakan yaitu dengan convenience sampling dengan pertimbangan kemudahan, seperti responden yang lebih mudah ditemui peneliti (Sugiarto, 2011). Responden dalam penelitian ini adalah konsumen pengguna angin Green Nitrogen dari tiga outlet dengan kriteria: (1) Pernah menggunakan angin Green Nitrogen dalam enam bulan terakhir. (2) Pernah menggunakan angin Green Nitrogen baik di tempat lain maupun di SPBU Bekasi Barat, SPBU Kelapa Gading Jakarta Utara dan SPBU Utan Kayu Rawamangun Jakarta Timur. Jumlah responden yang digunakan yaitu sebanyak 120 responden dengan 22 jenis atribut dalam kuesioner.

Penelitian ini dimulai dengan analisis deskriptif, yaitu untuk menjelaskan situasi dan karakteristik responden, serta mengumpulkan data relevan. Analisis ini bertujuan mendapatkan gambaran secara sistematis, faktual dan akurat mengenai fakta dan sifat serta hubungan antara fenomena yang diselidiki. Data karakteristik konsumen meliputi usia, jenis kelamin, pekerjaan, pendidikan, kepemilikan kendaraan bermotor. Data perilaku penggunaan meliputi frekuensi berkunjung, perolehan informasi, proses keputusan pembelian, pelayanan yang dibeli dan kesadaran akan merek Green Nitrogen. Analisis ini digunakan karena dinilai mampu untuk menggambarkan karakteristik konsumen dan perilaku pembelian.

Variabel yang digunakan dalam penelitian ini yaitu variabel demografi, variabel dimensi pengetahuan konsumen, variabel dimensi kualitas produk, variabel dimensi kepercayaan pelanggan dan variabel dimensi loyalitas pelanggan. Selanjutnya untuk mengkaji hubungan dan pengaruh setiap variabel menggunakan pendekatan SEM (Structural Equation Modelling). Penelitian ini menggunakan SEM dengan pendekatan Partial Least Square (PLS) dengan menggunakan software Smart PLS, PLS Graph, Visual PLS, dan PLS GUI (Ghozali, 2008).

Penelitianinibertujuanmenganalisis loyalitas pelanggan angin Green Nitrogen. Berdasarkan penelitian terdahulu oleh Richard dan Maxwell (2013) maka dapat diadopsi dan ditentukan model yang digunakan dalam penelitian ini yang tersaji pada Gambar 3. Penelitian Richard dan Maxwell (2013) dalam konteks ritel di Afrika menyatakan bahwa kepercayaan memiliki pengaruh positif terhadap loyalitas pelanggan. Selain itu, penelitian dilakukan oleh Deng et al. (2010) menyatakan bahwa kepercayaan, persepsi kualitas produk, nilai yang didapat pelanggan termasuk nilai fungsi dan nilai emosional merupakan atribut yang memengaruhi kepuasan pelanggan dan berpengaruh terhadap loyalitas pelanggan.

Model pada penelitian ini menghubungkan pengetahuan konsumen, kualitas produk dan kepercayaan pelanggan terhadap berpengaruh terhadap loyalitas pelanggan Green Nitrogen. Tujuan dari model ini, yaitu untuk mengetahui pengaruh atau hipotesis dari masingmasing varibel yang telah ditentukan. Hipotesis pertama bertujuan untuk mengetahui hubungan atau pengaruh variabel pengetahuan konsumen terhadap loyalitas pelanggan. Selanjutnya, hipotesis kedua untuk mengetahui apakah kualitas produk berpengaruh terhadap loyalitas pelanggan. Hipotesis tiga untuk mengetahui pengaruh kepercayaan pelanggan terhadap loyalitas pelanggan. Kerangka pemikiran penelitian pada Gambar 2.

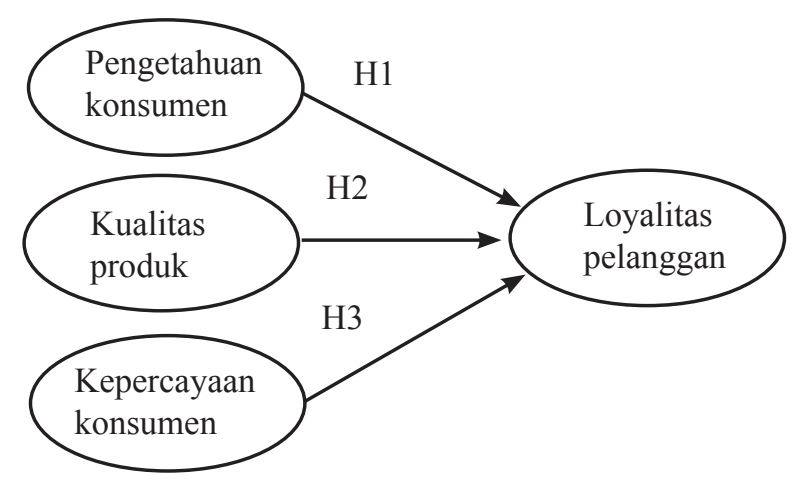

Gambar 2. Kerangka pemikiran penelitian 
Ha1 Pengaruh pengetahuan konsumen terhadap loyalitas konsumen

Dilakukan uji hipotesis pertama, yang akan menunjukkan apakah pengaruh pengetahuan konsumen terhadap loyalitas pelanggan signifikan atau tidak. Jika Ha1 diterima maka pengaruh pengetahuan konsumen terhadap loyalitas pelanggan adalah signifikan pada taraf nyata 0,05 demikian sebaliknya.

Ha2 Pengaruh kualitas produk terhadap loyalitas konsumen

Dilakukan uji hipotesis kedua, yang akan menunjukkan apakah pengaruh kualitas produk terhadap loyalitas pelanggan signifikan atau tidak. Jika Ha2 diterima maka pengaruh kualitas produk terhadap loyalitas pelanggan adalah signifikan pada taraf nyata 0,05 .

Ha3 Pengaruh kepercayaan pelanggan terhadap loyalitas konsumen

Selanjutnya akan diuji hipotesis ketiga, yang akan menunjukkan pengaruh kepercayaan pelanggan terhadap loyalitas pelanggan. Jika Ha3 diterima, maka pengaruh kepercayaan pelanggan terhadap loyalitas pelanggan adalah signifikan berpengaruh pada taraf nyata 0,05 .

\section{HASIL}

\section{Karakteristik Responden Berdasarkan Demografi}

Faktor loyalitas konsumen terhadap produk Green Nitrogen yang dipengaruhi faktor pengetahuan konsumen, kualitas produk itu sendiri dan kepercayaan konsumen, perlu dianalisa secara demografi. Aspek demografi dalam penelitian ini terdiri dari jenis kelamin, usia, tingkat pendidikan, jenis pekerjaan, rata-rata pengeluaran, dan jenis kendaraan responden. Masing masing karakteristik tersebut akan memengaruhi tingkat pengetahuan konsumen, respon terhadap kualitas yang diharapkan serta tingkat kepercayaan yang dihasilkan.

Informasi usia responden (Tabel 1) merupakan hal penting yang perlu diketahui karena usia yang berbeda akan menggambarkan selera konsumsi barang atau jasa yang berbeda (Sumarwan, 2011). Penelitian ini membagi usia menjadi empat kelompok umur. Hasil demografi berdasarkan usia menandakan bahwa responden dengan rentang usia 26-35 tahun dan 36-45 tahun merupakan responden yang memiliki kesadaran tinggi akan manfaat angin nitrogen terhadap ban kendaraan mereka.

Jenis kelamin responden terbagi menjadi dua kelompok, yaitu laki-laki dan perempuan. Hasil demografi berdasarkan kelamin menunjukkan bahwa persentase terbesar yang melakukan pembelian angin nitrogen adalah responden berjenis kelamin laki-laki yaitu sebesar $75,83 \%$. Pada umumnya laki laki memiliki kesadaran dan pengetahuan tentang perawatan kendaraan termasuk perawatan ban.

Aspek demografi jenis pekerjaan dibagi menjadi enam kelompok sebagaimana Table 2. Hasil penelitian menunjukkan bahwa responden sebagian besar memiliki jenis pekerjaan sebagai pegawai swasta (77\%), wiraswasta (13\%), dan pegawai negeri/BUMN (8\%). Kelompok pelajar/mahasiswa dan lainnya masing masing $1 \%$ dan $2 \%$ merupakan persentase yang rendah dalam hal kepedulian terhadap perawatan kendaraan termasuk ban.

Tingkat pendidikan merupakan tingkat terakhir yang dicapai responden. Aspek pendidikan dibagi dalam empat kelompok sebagaimana Tabel 3. Menurut Sumarwan (2015), tingkat pendidikan memengaruhi konsumen dalam memilih produk maupun merek. Konsumen yang memiliki tingkat pendidikan lebih baik akan lebih responsive terhadap informasi suatu produk. Tingkat pendidikan responden yang paling banyak mengunjungi Green Nitrogen pada penelitian ini adalah Sarjana (S1).

Tingkat pengeluaran yang dimaksud adalah rata-rata uang yang dibelanjakan responden dalam sebulan untuk konsumsi sehari-hari. Dengan mengetahui rata-rata pengeluaran responden, maka kebutuhan pasar, harapan dan tren pelanggan dapat diidentifikasi. Model konsumsi berdasarkan pengeluaran pelanggan akan dirancang dan menjadi informasi yang berguna untuk menguatkan hubungan pelanggan dengan perusahaan (Gibbert et al. 2002). Pengeluaran rata-rata dari calon responden akan berpengaruh terhadap jumlah uang yang dibelanjakan di outlet Green Nitrogen. Berdasarkan Tabel 4, bagian terbesar responden memiliki pengeluaran rata-rata per bulan sebesar Rp4.000.000-5.000.000 sebanyak 45,83\%. Artinya, sebagian besar konsumen Green Nitrogen merupakan kalangan menengah ke atas. Hal ini dapat dipahami dari kepemilikan kendaraan itu sendiri yang merupakan kategori barang mewah. 
Jenis kendaraan responden pada penelitian ini terbagi menjadi dua, yaitu mobil dan motor. Berdasarkan hasil penelitian dapat diketahui bahwa kedua jenis kendaraan baik motor maupun mobil memiliki persentase yang hampir seimbang dalam menggunakan jasa pelayanan angin Green Nitrogen, yaitu sebesar 51,67\% untuk motor dan mobil dengan persentase sebesar 48,33\%. Dapat diartikan bahwa kebutuhan akan angin nitrogen dengan merek Green Nitrogen berlaku untuk semua jenis kendaraan dan tidak didominasi jenis kendaraan tertentu.

Waktu pelayanan adalah lama waktu yang dihabiskan oleh konsumen dalam sekali kunjungan ke outlet Green Nitrogen. Hasil pengolahan data pada Tabel 5 memperlihatkan bahwa sebanyak $70 \%$ dari responden menghabiskan waktu rata-rata di outlet Green Nitrogen antara 6 menit hingga 10 menit dalam sekali kunjungan. Waktu yang dihabiskan konsumen di outlet Green Nitrogen menunjukkan lamanya pelayanan yang diberikan oleh Green Nitrogen sehingga kecepatan dan ketepatan pelayanan akan memengaruhi kepuasan dan loyalitas pelanggan.

Pengeluaran sekali kunjungan merupakan uang yang dikeluarkan konsumen di outlet Green Nitrogen. Aspek pengeluaran responden untuk perawatan atau pengisian angin Green Nitrogen dibagi empat kelompok sebagaimana Table 6 . Hasil penelitian adalah pengeluaran terbanyak dari responden melakukan transaksi rata-rata sebesar $\mathrm{Rp} 25.000-50.000$ atau sebesar $38,33 \%$.

\section{Pengaruh pengetahuan konsumen, kualitas produk, kepercayaan konsumen terhadap loyalitas pelanggan Green Nitrogen}

Pengujian hipotesis pada penelitian ini menggunakan metode PLS-SEM dengan bantuan aplikasi perangkat lunak SmartPLS Versi 2. Tujuan PLS untuk memprediksi pengaruh variabel $\mathrm{X}$ terhadap $\mathrm{Y}$ dan menjelaskan hubungan teoritis diantara kedua variabel. Metode analisis PLS dilakukan untuk mengetahui bentuk dan besarnya hubungan konstruk laten independen (endogen), yaitu loyalitas terhadap konstruk laten dependen (eksogen), yaitu pengetahuan konsumen, kualitas produk, dan kepercayaan konsumen.
Tabel 1. Informasi usia responden

\begin{tabular}{lcc}
\hline Usia & Total & \\
\hline $17-25$ tahun & 19 & $16 \%$ \\
$26-35$ tahun & 38 & $32 \%$ \\
$36-45$ tahun & 40 & $33 \%$ \\
$>45$ tahun & 23 & $19 \%$ \\
\hline Total & 120 & $100 \%$ \\
\hline
\end{tabular}

Tabel 2. Informasi jenis pekerjaan responden

\begin{tabular}{|c|c|c|}
\hline Pekerjaan & Total & \\
\hline Pegawai Negeri/BUMN & 10 & $8 \%$ \\
\hline Pegawai Swasta & 92 & $77 \%$ \\
\hline Wiraswasta & 15 & $13 \%$ \\
\hline Pelajar/Mahasiswa & 1 & $1 \%$ \\
\hline Lainnya & 2 & $2 \%$ \\
\hline Total & 120 & $100 \%$ \\
\hline
\end{tabular}

Tabel 3. Informasi tingkat pendidikan responden

\begin{tabular}{|c|c|c|}
\hline Tingkat Pendidikan & Total & \\
\hline SMP & 2 & $2 \%$ \\
\hline SMA & 35 & $29 \%$ \\
\hline Sarjana & 73 & $61 \%$ \\
\hline Pascasarjana (S2/S3) & 10 & $8 \%$ \\
\hline Total & 120 & $100 \%$ \\
\hline
\end{tabular}

Tabel 4, Tingkat pengeluaran responden per bulan

\begin{tabular}{|c|c|c|}
\hline Pengeluaran per bulan & Total & \\
\hline$<1$ juta & 1 & $0,83 \%$ \\
\hline 1 juta- 2 juta & 3 & $2,50 \%$ \\
\hline 2 juta- 3 juta & 15 & $12,50 \%$ \\
\hline 3 juta- 4 juta & 4 & $3,33 \%$ \\
\hline 4juta-5 juta & 55 & $45,83 \%$ \\
\hline$>5$ juta & 42 & $35,00 \%$ \\
\hline Total & 120 & $100 \%$ \\
\hline
\end{tabular}

Tabel 5. Sebaran responden berdasarkan tingkat waktu pelayanan

\begin{tabular}{lcc}
\hline Waktu Pelayanan & Total & \\
\hline$<5$ menit & 33 & $27,50 \%$ \\
6 menit -10 menit & 84 & $70,00 \%$ \\
11 menit -15 menit & 3 & $2,50 \%$ \\
\hline Total & 120 & $100 \%$ \\
\hline
\end{tabular}


Tabel 6. Sebaran responden berdasarkan tingkat pengeluaran untuk perawatan ban kendaraan

\begin{tabular}{lcc}
\hline Pengeluaran untuk ban & Total & \\
\hline$<24.000$ & 44 & $36,67 \%$ \\
$25.000-50.000$ & 46 & $38,33 \%$ \\
$51.000-74.000$ & 27 & $22,50 \%$ \\
$75.000-100.000$ & 3 & $2,50 \%$ \\
\hline Total & 120 & $100 \%$ \\
\hline
\end{tabular}

\section{Evaluasi Outer Model}

Hasil uji validitas konvergen pada Gambar 3 menunjukkan bahwa terdapat dua variabel indikator yang memiliki nilai koefisien outer loading dibawah 0,7 . Hal ini menunjukkan bahwa indikator tidak valid, sehingga model harus diestimasi kembali dengan mengeluarkan indikator yang memiliki nilai dibawah 0,7. Nilai AVE dan communalty pada variabel laten memiliki nilai yang valid. Dalam hal ini dilakukan estimasi kembali dengan mengeluarkan indikator yang memiliki nilai koefisien outer loading dibawah 0,7.

Model awal SEM yang diajukan dalam penelitian ini melibatkan indikator pada variabel laten consumer knowledge, quality product, dan customer trust. Hasil uji validitas konvergen pada Tabel 7, variabel laten pengetahuan konsumen semua indikatornya mempunyai nilai diatas 0,7 . Pada kualitas produk menunjukkan bahwa semua indikator yang menggambarkan kualitas produk memiliki nilai diatas 0,7 yang berarti semua indikator valid. Sebaliknya, pada kepercayaan pelanggan terdapat dua indikator yang harus dikeluarkan dari model. Kedua indikator tersebut adalah kenyamanan dalam bertransaksi (X31) dan kejujuran dan ketepatan dalam bertransaksi (X32).

\section{Evaluasi Inner Model}

Evaluasi inner model merupakan evaluasi yang dilakukan terhadap model struktural, yaitu pengukuran pada hubungan antara variabel dependen dan independen yang diajukan pada model. Parameter yang digunakan untuk evaluasi inner model dalam Smart PLS adalah koefisien determinan (uji R2) dan t-value. Menurut Wiyono (2011), uji model untuk inner model (uji hipotesis) menghasilkan dua output, yaitu R-Square untuk variabel laten endogen dan koefisien parameter dan t-Statistik. Nilai $\mathrm{R}$ digunakan untuk mengukur seberapa besar variabel dependen dapat dipengaruhi oleh variabel independen, sedangkan nilai t-value menunjukkan signifikansi pengaruh antar variabel laten dalam model struktural pada pengujian hipotesis (Abdillah dan Jogiyanto, 2009). Berdasarkan Gambar 4 dapat dilihat bahwa nilai R-Square dari masing-masing variabel laten endogen, yaitu pengetahuan konsumen 0,093, kualitas produk sebesar 0,136 dan kepercayaan konsumen sebesar 0,371. Hal ini mengidentifikasikan bahwa model lemah dan moderat.

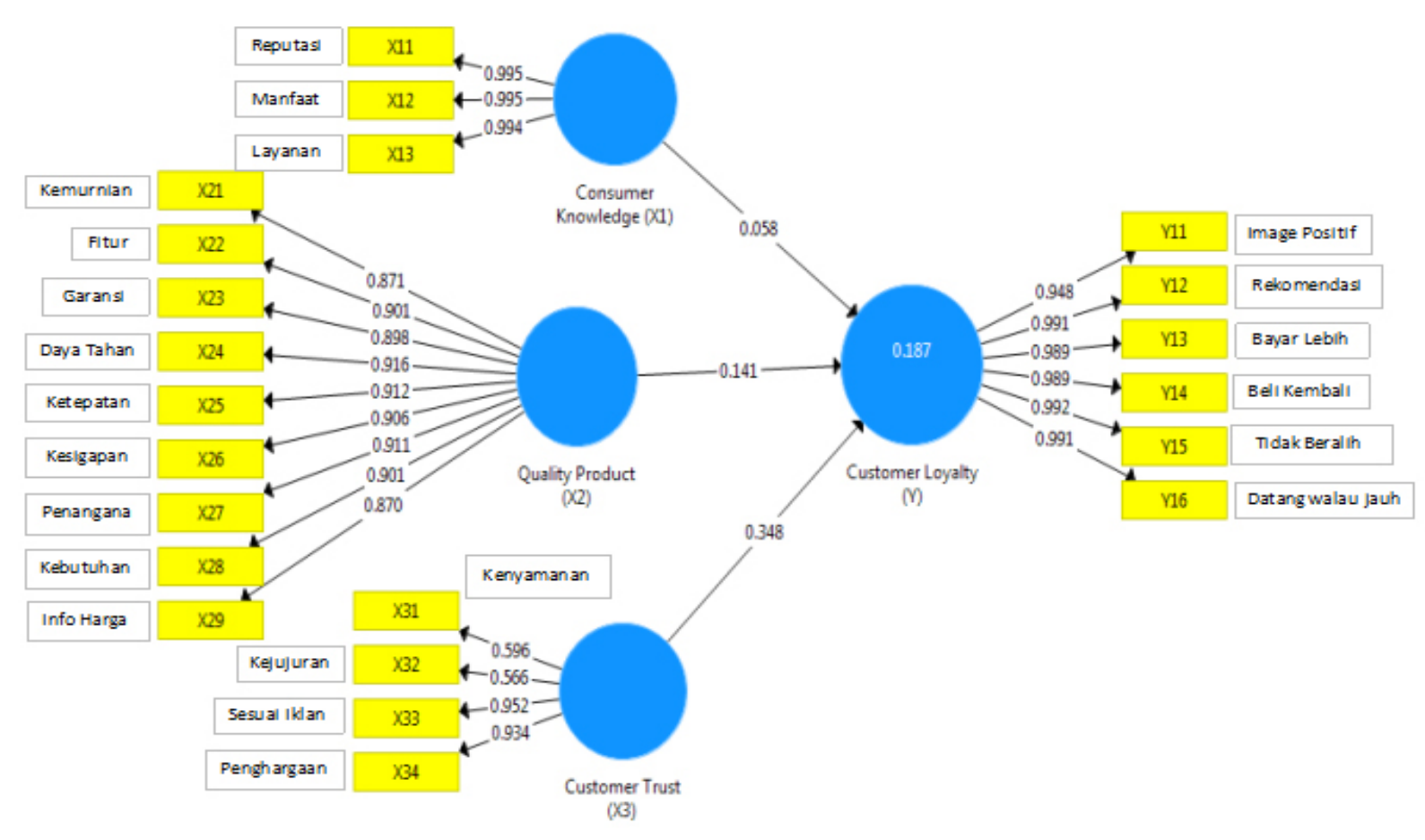

Gambar 3. Model awal SEM 
Tabel 7, Nilai outer loading hasil uji validitas konvergen

\begin{tabular}{|c|c|c|c|c|c|c|c|c|c|}
\hline & $\begin{array}{c}\text { Consumer } \\
\text { Knowledge } \\
\text { (X1) }\end{array}$ & $\begin{array}{l}\text { Customer } \\
\text { Loyalty } \\
\text { (Y) }\end{array}$ & $\begin{array}{l}\text { Customer } \\
\text { Trust (X3) }\end{array}$ & $\begin{array}{c}\text { Quality } \\
\text { Product } \\
\text { (X2) }\end{array}$ & & $\begin{array}{c}\text { Consumer } \\
\text { Knowledge } \\
\text { (X1) }\end{array}$ & $\begin{array}{l}\text { Customer } \\
\text { Loyalty } \\
\text { (Y) }\end{array}$ & $\begin{array}{l}\text { Customer } \\
\text { Trust (X3) }\end{array}$ & $\begin{array}{l}\text { Quality } \\
\text { Product } \\
\text { (X2) }\end{array}$ \\
\hline $\mathrm{X} 11$ & 0,995 & & & & X29 & & & & 0.87 \\
\hline $\mathrm{X} 12$ & 0,995 & & & & $\mathrm{X} 31$ & & & 0,596 & \\
\hline $\mathrm{X} 13$ & 0,994 & & & & $\mathrm{X} 32$ & & & 0,566 & \\
\hline $\mathrm{X} 21$ & & & & 0,871 & X33 & & & 0,952 & \\
\hline $\mathrm{X} 22$ & & & & 0,901 & X34 & & & 0,934 & \\
\hline $\mathrm{X} 23$ & & & & 0,898 & Y11 & & 0,948 & & \\
\hline $\mathrm{X} 24$ & & & & 0,916 & Y12 & & 0,991 & & \\
\hline $\mathrm{X} 25$ & & & & 0,912 & Y13 & & 0,989 & & \\
\hline $\mathrm{X} 26$ & & & & 0,906 & Y14 & & 0,989 & & \\
\hline $\mathrm{X} 27$ & & & & 0,911 & Y15 & & 0,992 & & \\
\hline $\mathrm{X} 28$ & & & & 0,901 & Y16 & & 0,991 & & \\
\hline
\end{tabular}

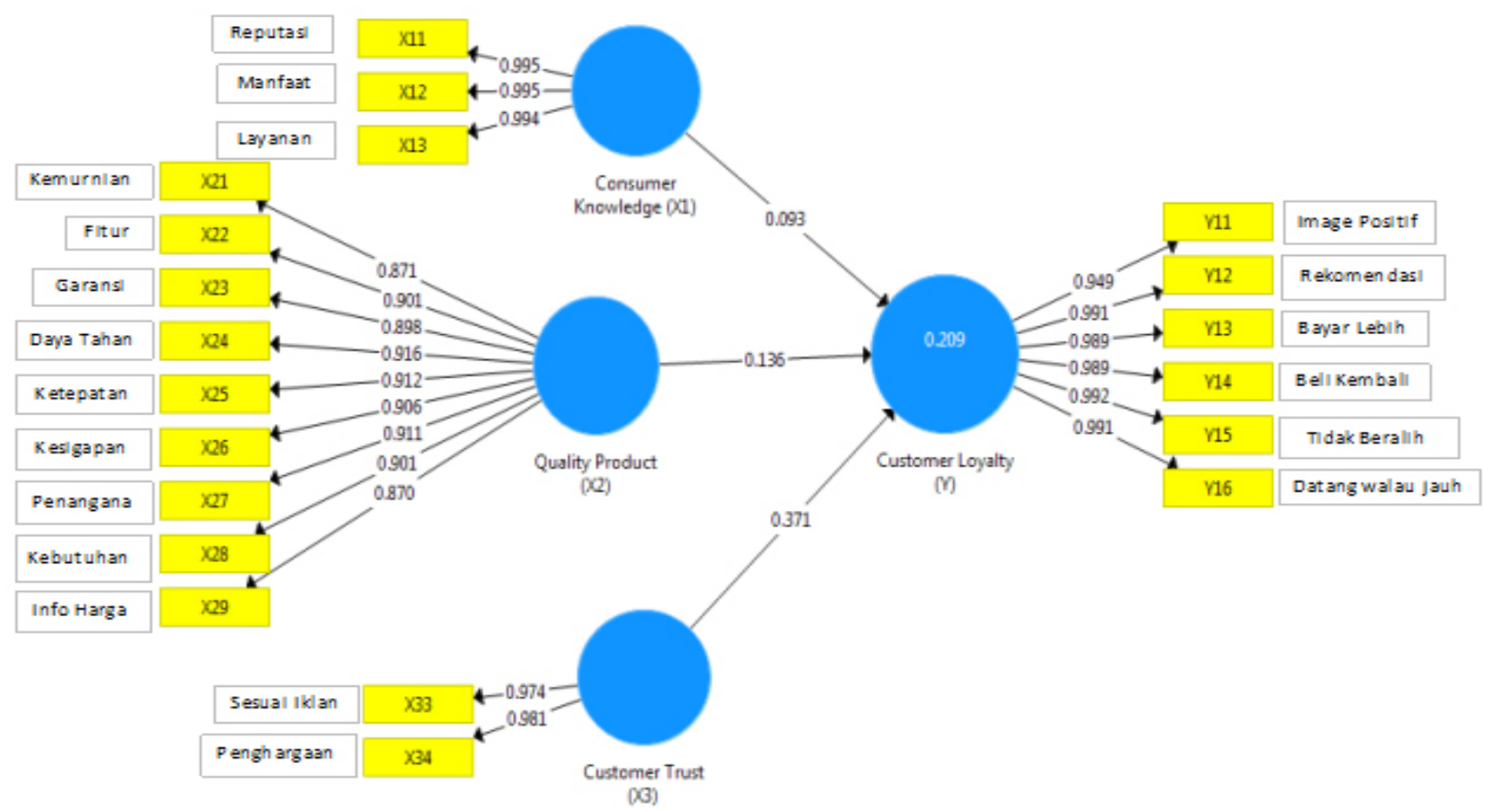

Gambar 4. Model akhir SEM

Pengujian hipotesis dilakukan dengan menggunakan analisis bootstrapping pada path coefficients, yaitu dengan membandingkan $\mathrm{t}_{\text {hitung }}$ dengan $\mathrm{t}_{\text {tabel }}$. Jika nilai $t_{\text {hitung }}>t_{\text {tabel }}(1,96)$ maka perumusan hipotesis diterima, namun jika nilai $\mathrm{t}_{\text {hitung }}<\mathrm{t}_{\text {tabel }}(1,96)$ maka perumusan hipotesis ditolak. Hasil analisis bootstrapping pada pathcoefficients dari model ini berdasarkan nilai t-tabel pada selang kepercayaan $95 \%$ dapat dilihat pada Tabel 8 dimana hipotesis yang diajukan hanya 3 hipotesis yang diterima sebanyak 1 hipotesis sedangkan 2 hipotesis lainnya ditolak.
Hasil nilai bootstrap pada koefisien path didapatkan kepercayaan pelanggan (CT) secara langsung berpengaruh positif dan signifikan terhadap loyalitas pelanggan (CL) pada taraf nyata 0,05 (nilai $\mathrm{p}$ value $<0,05$ ). Kualitas produk dan pengetahuan konsumen secara langsung berpengaruh terhadap loyalitas pelanggan. Namun, tidak menunjukkan pengaruh yang signifikan pada taraf nyata 0,05 . Green Nitrogen perlu memperhatikan strategi-strategi yang berkaitan dengan pemasaran untuk meningkatkan pengetahuan konsumen dan strategi untuk meningkatkan kualitas produk untuk mempertahankan loyalitas pelanggan. 
Tabel 8. Nilai hasil bootstrap

\begin{tabular}{cccccc}
\hline Variabel laten & Original Sample (O) & Sample Mean $(\mathrm{M})$ & $\begin{array}{c}\text { Standard Deviation } \\
(\mathrm{STDEV})\end{array}$ & $\begin{array}{c}\text { T Statistics } \\
(|\mathrm{O} / \mathrm{STDEV}|)\end{array}$ & $\begin{array}{c}\text { Hasil pengujian } \\
\text { hipotesis }\end{array}$ \\
\hline $\mathrm{CT} \rightarrow \mathrm{CL}$ & 0,371 & 0,372 & 0,086 & $4,293^{* *}$ & Diterima \\
$\mathrm{QL} \rightarrow \mathrm{CL}$ & 0,136 & 0,142 & 0,093 & 1,467 & Ditolak \\
$\mathrm{CK} \rightarrow \mathrm{CL}$ & 0,093 & 0,09 & 0,092 & 1,013 & Ditolak \\
\hline
\end{tabular}

**signifikan pada taraf nyata 0,05 dengan $\mathrm{T}$ tabel $=1,96$

Ha1 Pengaruh pengetahuan konsumen terhadap loyalitas konsumen

Hasil uji hipotesis pertama menunjukkan bahwa pengaruh pengetahuan konsumen terhadap loyalitas pelanggan, Ha1 ditolak. Artinya, pengaruh pengetahuan konsumen terhadap loyalitas pelanggan adalah tidak signifikan pada taraf nyata 0,05 . Tidak signifikannya pengaruh pengetahuan konsumen ini terhadap loyalitas Green Nitrogen lebih disebabkan pengenalan merek dimana konsumen menganggap bahwa semua outlet pengisian angin nitrogen adalah sama, yaitu sama sama berisi nitrogen. Pengetahuan konsumen ini baru sebatas angin biasa dibandingkan dengan angin nitrogen, sedangkan pengenalan merek masih rendah.

Ha2 Pengaruh kualitas produk terhadap loyalitas konsumen

Hasil uji hipotesis kedua menunjukkan bahwa pengaruh kualitas produk terhadap loyalitas pelanggan, Ha2 ditolak. Artinya, pengaruh kualitas produk terhadap loyalitas pelanggan tidak signifikan pada taraf nyata 0.05 . Tidak signifikannya pengaruh faktor kualitas produk ini terhadap loyalitas Green Nitrogen bukan berarti konsumen tidak peduli terhadap kualitas, melainkan menganggap bahwa kualitas Green Nitrogen dengan merek lain adalah sama, sehingga pihak Green Nitrogen harus memberikan informasi atau sosialisasi yang sangat berbeda agar konsumen paham benar bahwa kualitas Green Nitrogen lebih baik dan tidak dimiliki outlet lain. Dengan demikian, loyalitas ini tidak hanya beralih dari pengisian angin biasa ke angin nitrogen. Namun, angin nitrogen yang dipilih adalah merek Green Nitrogen. Pelanggan akan puas jika perusahaan memberikan kualitas produk yang sesuai harapan pelanggan.

Hasil penelitian memiliki persamaan dengan penelitian yang dilakukan oleh Hidayat (2009) yang menunjukkan bahwa kualitas produk berpengaruh negatif dan nonsignifikan terhadap loyalitas nasabah. Baiknya kualitas produk yang diberikan perusahaan kepada nasabah belum tentu membuat nasabah menjadi loyal kepada Bank. Penelitian Minh (2016) terhadap 261 responden perbankan ritel di Vietnam mengatakan ada hubungan timbal balik antara kualitas layanan, kepuasan pelanggan, dan kesetiaan pelanggan dalam konteks perbankan ritel. Penelitian lain Izogo (2017), terhadap 138 pengguna telepon selular di salah satu kota tenggara Nigeria menemukan bahwa memengaruhi loyalitas pelanggan melalui komitmen pelanggan dengan memanfaatkan dua konstruk kualitas layanan, yaitu jaminan layanan dan keandalan layanan (Amjad, 2011).

Ha3 Pengaruh kepercayaan pelanggan terhadap loyalitas konsumen

Hasil uji hipotesis ketiga, pengaruh kepercayaan pelanggan terhadap loyalitas pelanggan, $\mathrm{Ha} 3$ diterima. Artinya, pengaruh kepercayaan pelanggan terhadap loyalitas pelanggan adalah signifikan berpengaruh pada taraf nyata 0,05 . Berpengaruhnya faktor kepercayaan pelanggan terhadap loyalitas Green Nitrogen menunjukkan bahwa kepercayaan adalah masalah selera atau terdapat unsur afektif sehingga apa yang sudah menjadi keyakinan akan memengaruhi proses pengambilan keputusan. Faktor kepercayaan ini juga terkait dengan kesadaran tentang performance kendaraan sehingga pelanggan tidak akan mencoba produk lain yang belum diyakini.

Penelitian yang dilakukan oleh Yap et al. (2012), menunjukkan bahwa adanya kepercayaan berpengaruh positif signifikan terhadap loyalitas pelanggan bank. Oleh karena itu, perusahaan harus fokus membangun tingkat kepercayaan pelanggan bahwa pelayanan yang diberikan sesuai dengan janji yang diberikan serta memberikan pelayanan terbaik untuk pelanggannya. Hal ini sejalan dengan penelitian Chang (2006) dimana kepercayaan pelanggan terdiri dari kepercayaan afektif dan kognitif. Pada kepercayaan konsumen kognitif yakin bahwa penyedia layanan kompeten 
dan handal dalam menepati janji. Studi Bansal et al. (2004) menunjukkan adanya hubungan positif yang signifikan antara kepercayaan pelanggan dan loyalitas pelanggan.

\section{Implikasi Manjerial}

Kepercayaan konsumen merupakan varibel utama yang paling berpengaruh dalam membentuk loyalitas pelanggan. Manajemen perlu terus menjaga reputasi, kejujuran dan mensosialisasikan penghargaan atau award yang didapat. Dalam aspek pengetahuan konsumen, manajemen perlu memperkuat perbedaan berupa logo, seragam karyawan agar menjadi pembeda dengan outlet merek lain. Dalam hal kualitas produk perlu dilakukan sebuah jaminan atau garansi jika tidak sesuai klaim atau janji di brosur. Perlu dilakukan pelatihan karyawan agar dapat memberikan pelayanan yang lebih ramah. Perlu juga menambah produk atau layanan tambahan sehingga nilai transaksi dari ratarata $\mathrm{Rp} 25.000-50.000$ dapat ditingkatkan misalnya layanan cuci mobil atau ganti oli, ganti aki, pemasangan stiker, aksesoris dan sebagainya. Dari sisi demografi, manajemen perlu lebih memperhatikan dan menggali kebutuhan dari pelanggan terbesar yaitu berjenis kelamin laki-laki, dari sisi usia antara 26-45 tahun serta berpendidikan sarjana.

\section{KESIMPULAN DAN SARAN}

\section{Kesimpulan}

Hasil penelitian denagn analisis SEM menunjukkan bahwa faktor-faktor yang berpengaruhterhadaployalitas pelanggan Green Nitrogen secara berurutan dari yang paling besar pengaruhnya sampai yang terkecil adalah aspek kepercayaan pelanggan dengan R-Square 0,371 disusul aspek kualitas produk dengan R-Square 0,136 dan pengetahuan konsumen dengan R-Square 0,093. Hasil penelitian menunjukkan bahwa pengetahuan konsumen dan kualitas produk tidak berpengaruh signifikan terhadap loyalitas konsumen Green Nitrogen. Sebaliknya, kepercayaan pelanggan mempunyai pengaruh terhadap loyalitas pelanggan. Indikator kepercayaan konsumen adalah keyakinan bahwa Green Nitrogen memberikan bukti terhadap janji yang tertera di brosur atau di bilboard serta kepercayaan bahwa Green Nitrogen mempunyai reputasi yang dibuktikan dengan didapatnya penghargaan atau award.

\section{Saran}

Saran untuk penelitian selanjutnya adalah menggunakan kepuasan pelanggan sebagai jembatan bagi konsumen menggunakan produk Green Nitrogen lagi. Di samping itu, juga meneliti variabel yang diambil dari teoriteori lain yang membentuk loyalitas pelanggan seperti menggunakan perceived value, kepuasan pelanggan, dan harga. Demikian juga terkait motivasi dan kebutuhan lanjutan antara pengendara roda dua dan roda empat.

\section{DAFTAR PUSTAKA}

Abdillah W, Jogiyanto HM. 2009. Konsep dan Aplikasi PLS (Partial Least Square) Untuk Penelitian Empiris. Yogyakarta: Badan Penerbit Fakultas Ekonomi.

Alba J, Hutchinson WJ. 1987. Dimensions of Consumer Expertise. Journal of Consumer Research 13: 411-454. https://doi.org/10.1086/209080.

Amjad A. 2011. Towards an integrated model of customer service skills and customer loyalty. the mediating role of customer satisfaction. International Journal of Commerce and Management 21(4): 349-380. https://doi. org/10.1108/10569211111189365.

Bansal HS, Irving PG, Taylor SF. 2004. A threecomponent model of customer commitment to service providers. Journal of the Academy of Marketing Science 32(3): 234-245. https://doi. org/10.1177/0092070304263332.

Brucks M, Zeithaml VA, Naylor G. 2000. Price and brand name as indicators of quality dimensions for consumer durables. Journal of the Academy of Marketing Science 12(1): 97-100. https://doi. org/10.1177/0092070300283005.

Chang JC. 2006. Customer satisfaction with tour leaders' performance: a study of Taiwan's package tours. Asia Pacific Journal of Tourism Research 11(1):97-116.

Deng Z, Lu Y, Wei K, Zhang, J. 2010. Understanding customer's satisfaction and loyalty: an empirical study of mobile instant messages in China. International Journal of Information Management 30 (4): 289-300. https://doi. org/10.1016/j.ijinfomgt.2009.10.001.

Devaraj S, Matta KF, Edward C. 2001. Product and service quality: the antecedents of customer loyalty in the automotive industry. Production 
and Operations Management 10(4):424-439. https://doi.org/10.1111/j.1937-5956.2001. tb00085.x.

Ghozali I. 2009. Aplikasi Analisis Multivariate dengan Program SPSS. 4th ed. Semarang: Universitas Diponogoro.

Gibbert M, Leibold, Probst G. Five styles of customer knowledge management, and how smart companies use them to create value. European Management Journal 20(5):459-469. https:// doi.org/10.1016/S0263-2373(02)00101-9.

Heizer J, Render B. 2006. Manajemen Operasi, Edisi 7. Jakarta: Salemba Empat.

Hong IB, Cho H. 2011. The impact of consumer trust on attitudinal loyalty and purchase intention in B2C e-market place: intermediary trust vs seller trust. International Journal of Information Management 31(11): 469-479. https://doi. org/10.1016/j.ijinfomgt.2011.02.001.

Izogo EE. 2017. Customer loyalty in telecom service sector: the role of service quality and customer commitment. TQM Journal; Bingley 29(1): 19-36. https://doi.org/10.1108/TQM-10-20140089.

Komejani SMM, Mohaghegh. 2017. The effects of customer knowledge management in improving customer loyalty in private educational institutions. International Conference on Intellectual Capital and Knowledge Management and Organisational Learning; Kidmore End. 15(41): 366-375.

Minh NV. 2016. The relationship between service quality, customer satisfaction and customer loyalty: an investigation in Vietnamese retail banking sector. Nguyen Huan Huu Journal of Competitiveness 8(2):103-116. https://doi. org/10.7441/joc.2016.02.08.

Morgan H. 1994. The commitment - trust theory of relationship marketing. Journal of Marketing 58(1): 20-38. https://doi. org/10.1177/002224299405800302.

Mowen JC, Mirror M. 2002. Perilaku Konsumen. Jakarta: Penerbit Erlangga.

Oliver RL. 1999. Whence consumer loyalty? Journal of Marketing 63: 33-44. https://doi. org/10.2307/1252099.

Rachmad H. 2009. Pengaruh kualitas layanan, kualitas produk dan nilai nasabah terhadap kepuasan dan loyalitas nasabah Bank Mandiri. Jurnal Manajemen dan Kewirausahaan 11(1): 59-72.

Richard C, Maxwell S. 2013. Customer satisfaction, trust and loyalty as predictors of customerintention to re-purchase South African retailing industri. Mediterranean Journal of Social Sciences 4(14): 437-446.

Sugiarto. 2011. Teknik Sampling. Jakarta: Gramedia Pustaka Utama.

Sumarwan U. 2015. Perilaku Konsumen Teori dan Penerapan dalam Pemasaran. Ed Ke-2. Jakarta: Ghalia.

Wijaya A. 2013. Angin Perubahan, Menjual Angin Dengan Cara Luar Biasa. Jakarta: Expose.

Wiyono G. 2011. Merancang Penelitian Bisnis dengan Alat Analisis SPSS 17.0 dan Smartpls 2.0. Yogyakarta: UPP STIM YKPN.

Yap BW, Ramayah T, Shahidan WNW.2012. Satisfaction and trust on customer loyalty: a PLS approach. Business Strategy Series 13(4):154-167. https:// doi.org/10.1108/17515631211246221. 